\title{
A Protocol for Fish Lipid Analysis Using Nuclear Magnetic Resonance Spectroscopy
}

\author{
Natalia Cristina Mor, ${ }^{a}$ Banny S. B. Correia ${ }^{b}$ Adalberto Luis Val and Ljubica Tasic $^{\circledR *, b}$ \\ ${ }^{a}$ Faculdade de Ciências Farmacêuticas, Universidade Estadual de Campinas, \\ R. Cândido Portinari, 200, Cidade Universitária, 13083-871 Campinas-SP, Brazil \\ ${ }^{b}$ Departamento de Química Orgânica, Instituto de Química, Universidade Estadual de Campinas, \\ Rua José de Castro, s/n, Cidade Universitária, 13083-970 Campinas-SP, Brazil \\ ${ }^{c}$ Laboratório de Ecofisiologia e Evolução Molecular, Coordenação de Biodiversidade, \\ Instituto Nacional de Pesquisas da Amazônia, Avenida André Araújo, 2936, \\ Petrópolis, 69067-375 Manaus-AM, Brazil
}

\begin{abstract}
This article reports on an easy-to-follow methodology for fish lipids analysis, including the biological sample collection, lipid extraction, sample preparation, nuclear magnetic resonance (NMR) spectroscopy analysis and statistical data analysis, with details on parameters used for the NMR analysis and the care needed in each step execution. As an example of the biological matrix of lipids, for the entire procedure, we have used two Amazonian fish samples. Phenotype factor was taken into account when lipid contents of the Amazonian fish samples were evaluated, such as fish-eating habits in distinct Amazon seasonal periods, the flood and the drought. Results demonstrated the applicability of NMR as a powerful and useful tool for fish oil analysis. The omnivorous (T. elongatus) and the piscivorous (C. monoculus) Amazonian fish differ in composition and distribution of lipids, which show differences not only because of the different eating habits between the two species, but also by the availability and quantity of food along the year, i.e., during the flood and drought Amazon periods.
\end{abstract}

Keywords: lipid analysis, Amazonian fish, nuclear magnetic resonance spectroscopy

\section{Introduction}

One of the most promising techniques for lipid analysis in biological tissues is nuclear magnetic resonance (NMR) spectroscopy, which is a high-resolution non-destructive method. NMR provides rapid data acquisition and does not require derivatization of the samples that other lipid analysis methods require. ${ }^{1-6}$ Studies of fish oils were widely performed using the NMR technique $e^{4,5,7}$ ever since essential fatty acids, which are widely found in fish, such as docosahexaenoic acid (DHA, 22:6n-3) and eicosapentaenoic acid (EPA, 20:5n-3), ${ }^{8,9}$ have become part of a diet recommended by nutritionists. The consumption of these biomolecules has been shown to be related to the reduction of risks associated with inflammatory, cardiovascular, immunological, neurological and visual disorders, various types of cancer, and also can influence human growth and development. ${ }^{8-22}$

In particular, the fish liver has a high concentration of lipids due to its metabolic characteristic related to energy

*e-mail: 1jubica@unicamp.br homeostasis. It is the main site of detoxification, deposition, transport, degradation and lipid synthesis. ${ }^{10,12,23,24}$ There are intrinsic and extrinsic factors that can affect the expression of hepatic genes involved in the metabolic regulation of lipids and energy, influencing the percentage of these molecules, which may also vary according to the characteristics of each species, food habit, food intake, age, lipid storage, and processing. ${ }^{10,12,25-28}$ In addition, the biochemical composition of fish is influenced by habitat in which it lives, known as phenotype factor.

Despite the great advantages of NMR, a choice of the most suitable protocol for isolation, fractionation, and analysis of fish oils must be discussed before NMR analysis, since fish oils are very complex mixtures and the way of preparing a lipid sample must lead to a reproducible and accurate protocol. The lipids are classified in eight categories within different chemical characteristics: fatty acids, glycerolipids, glycerophospholipids, sphingolipids, sterol lipids, prenols, saccharolipids and polyketides..$^{29}$ These categories of lipids may show a high diversity of molecules. There are two precursors of lipids, the isoprenyl and the acetyl, as well as the random combination of 
their three different building blocks, namely glycerol, fatty acids, and polar head group, which lead to many combinations. They can present glycerol in distinct forms, tri-, di-, and monoacylglycerol; monoglyceroether; and monoglyceroplasmalogen. Furthermore, the fatty acyl composition can differ, specifically in the length of the carbon chains, the number of double bonds present, the double bond position(s), the position of the acyls, and their oxidization. In addition, polar group can vary between amino alcohol, choline, ethanolamine, serine, glycerol, glycerophosphate, inositol, phosphate, cytidine5 '-diphosphate (CDP), and glucose. Investigators have estimated that around 180,000 lipid molecules exist in nature, with around 40 common fatty acids as their building blocks. $^{30}$

As Amazon River is subjected to variable changes and many phenotypes and, so far, is one of the least researched regions, we decided to verify if the proposed bioanalytical protocol is applicable for accurate lipids assessment by studying two species of Amazonian fish. Two of the most economically important species of the region, the Tucunare (Cichla monoculus, C. monoculus) and the Amazonian Sardine (Triportheus elongatus, T. elongatus), were chosen and their lipids were evaluated at two Amazon seasons, the flood and the drought periods. The flood, between May and June, occurs when the water level reaches its apex and much of the region is flooded; and the drought, between October and November, occurs when the area and volume of water reach their minimum and the fish are confined in a smaller volume of water. ${ }^{25}$ We have chosen the two Amazon River periods because the availability of food throughout the year is strongly influenced by the numerous factors, such as climate and hydrological cycle, which depend on the seasonal period. ${ }^{25,28}$

However, lipid analysis is not a simple task due to the fact that biological material contains active enzymes capable of causing undesired oxidation because of the high degree of carbon chain unsaturation..$^{31,32}$ Thus, the choice of the appropriate methodology is fundamental to guarantee the integrity of the samples and the efficiency of the processes involved in the extraction and purification of lipids, which directly influence the final quality of the lipid fraction. ${ }^{33}$ Thus, herein we have proposed an easy to follow methodology for lipid analysis of fish oils.

\section{Experimental}

\section{Material selection and collection}

The fish samples from C. monoculus and T. elongatus were collected at the same points during the drought and flood Amazonian periods in 2014 (1-6, Figure S1, Supplementary Information (SI) section), using nets, in two periods of the day. The coordinate points were marked and maintained during the recollection. The collection was authorized by Brazilian Institute of the Environment and Renewable Natural Resources (IBAMA, license No. 29837 and 39985) and the fishes were collected with sizes superior to those of their respective sexual maturity, regardless of gender. The length of fishes was measured using a ruler, and the ones bigger than the size $(\mathrm{cm})$ indicated for the species as correct to their plain sexual maturity were kept. Those fishes were put into iceboxes with water for $1 \mathrm{~h}$. In the present study, for $T$. elongatus, sizes above $17 \mathrm{~cm}$ and for $C$. monoculus sizes above $19 \mathrm{~cm}$ in both periods, according to specific literature were kept. ${ }^{28,34}$ The fishes were euthanized according to national animal care regulations and were approved by the Ethics Committee on Animal Experiments of INPA under registration No. 026/2015. The number of samples collected was at least 2 and at most of 8 per species. Livers from fish were removed using a scalpel and forceps after washing each fish and fish were cut from the anus to the mouth with surgical scissors. To remove livers a sanitized place was maintained. The fishes were washed prior to handling, a sheet of filter paper was maintained and exchanged for each specimen in the fish handling table, distilled water and $70 \%$ alcohol were used in the handling the scalpel and knife, and the scalpel blade was changed for each sample, as well as the use of an ice box for manipulation of the samples. Livers were transferred to the sterile Falcon tubes and stored in freezer at $-20^{\circ} \mathrm{C}$. A total of 22 liver samples were obtained during the flood and drought seasons (Table 1), ten samples were from the flood period, and twelve from the drought.

\section{Lipid extraction}

The method used for lipid extraction was adapted from Bligh and Dyer. ${ }^{31}$ Around $0.5 \mathrm{~g}$ of the fish liver were placed in a mortar, covered with a liquid nitrogen, and macerated

Table 1. Fishes collected during flood and drought periods of Amazon River

\begin{tabular}{lccccc}
\hline \multirow{2}{*}{ Fish } & \multicolumn{2}{c}{ Flood } & & \multicolumn{2}{c}{ Drought } \\
\cline { 2 - 3 } \cline { 5 - 6 } & Exemplar / unity & Size / cm & & Exemplar / unity & Size / cm \\
\hline C. monoculus & 4 & $24.63 \pm 4.89$ & 6 & $24.90 \pm 2.33$ \\
T. elongatus & 6 & $17.50 \pm 2.30$ & 6 & $17.58 \pm 1.69$ \\
\hline
\end{tabular}


with the pistil. Then, the material was put into a $40 \mathrm{~mL}$ test tube and a mixture of methanol, chloroform (LabSynth, Brazil) and MilliQ water in 2:1:1 (v/v/v) ratio was added and maintained for $2 \mathrm{~min}$ in vortex. After filtering the material using Büchner funnel equipped with the filter paper $80 \mathrm{G}$, the filtered liquid sample was transferred into a test tube. Then, liquid sample was centrifuged for $20 \mathrm{~min}, 1,694 \times \mathrm{g}$ at $25^{\circ} \mathrm{C}$. The upper phase (hydroalcoholic) was removed with a Pasteur pipette and the chloroform phase (lower phase) was reserved. To the hydroalcoholic phase, $10 \mathrm{~mL}$ of chloroform were added, and the process of liquid/liquid extraction was repeated. The chloroform phases were jointed and the hydroalcoholic phase was discarded. Previously, the method was validated in a muscle sample from Amazonian fish, using nonadecanoic acid (C19:0) as internal standard, ${ }^{35}$ where just a minimal lipid lost was achieved (less than $0.01 \%$ ). The chloroform phase was transferred into a $250 \mathrm{~mL}$ round bottom flask, and the lipids were recovered after using an evaporator at a temperature of $60^{\circ} \mathrm{C}$. Lipids were transferred into a labeled bottle with a minimal but sufficient amount of chloroform, which was evaporated at room temperature $\left(25^{\circ} \mathrm{C}\right)$ under the nitrogen atmosphere and weighed. Fish liver lipids were stored in a refrigerator at $-20{ }^{\circ} \mathrm{C}$.

\section{Fractionation of lipid extracts}

The method used for lipid fractionation was adopted from Johnston et al. ${ }^{36}$ work. $0.05 \mathrm{~g}$ of fish liver lipids were solubilized in $1 \mathrm{~mL}$ of chloroform and introduced into a $0.5 \mathrm{~cm}$ diameter glass column containing $5 \mathrm{~cm}$ of silica gel 63-200 $\mu \mathrm{m}$ and $1 \mathrm{~cm}$ of anhydrous sodium sulfate at the top of the column. The silica gel and anhydrous sodium sulfate were previously heated in an oven $\left(80{ }^{\circ} \mathrm{C}\right)$ for the removal of residual moisture. Lipid fractions with different polarities were obtained by elution with $10 \mathrm{~mL}$ of chloroform (100\%), $10 \mathrm{~mL}$ of acetone $(100 \%)$, and $10 \mathrm{~mL}$ of methanol $(100 \%)$. All solvents were purchased from LabSynt (Brazil). When amount of fish liver lipids was lower than the minimum quantity of sample required for this experiment, lipids that referred to the same fish from the same period of the year were combined to obtain sufficient amount for the column separation into neutral lipids, glycolipids, and phospholipids, respectively. The samples were kept at $-20{ }^{\circ} \mathrm{C}$ for posterior analyses. The lipid fractions were evaluated by thin layer chromatography (TLC) method using the normal phase silica plates (Merck, Germany) as the stationary phase, an elution system composed of $n$-hexane, ethyl ether and acetic acid in the ratio of 80:16:4 (v/v/v), respectively, and a $20 \%$ ethyl acetate phosphomolybdic acid solution (v/v) as developer. ${ }^{35,37}$ The samples were applied using capillary, and then the plate was exposed to the eluents in a chromatographic vessel and finally to the developer, which was sprayed over the entire area of the plate. After drying of the developer, the plate was slowly heated to about $80^{\circ} \mathrm{C}$ for the appearance of the bands for analysis of the retention factors.

\section{Sample preparation and ${ }^{1} \mathrm{H}$ NMR analysis}

$5.0 \mathrm{mg}$ of a lipid sample of interest (fish liver lipid sample or fraction of the lipid sample) were solubilized in $600 \mu \mathrm{L}$ of deuterated chloroform (99.8\% purity, Cambridge Isotope Laboratories, Inc.) and transferred to NMR tube ( $5 \mathrm{~mm}$ diameter). Qualitative and quantitative analyzes by ${ }^{1} \mathrm{H}$ NMR spectroscopy were performed at the Institutional NMR Laboratory of the Chemistry Institute at University of Campinas (Campinas, Brazil) where the equipment used was the Bruker ${ }^{\circledR}$ high resolution $600 \mathrm{MHz}$. Sample were analyzed using two probes, triple resonance broadband inverse (TBI) to qualitative analysis and broadband inverse (BBI) to quantitative analysis. Used conditions were: $90^{\circ}$ pulse (zg sequence), pulse power of $27 \mathrm{~W}, 64 \mathrm{k}$ data points, with a spectral width of $12,335 \mathrm{~Hz}$, an acquisition time of $2.66 \mathrm{~s}$, a fixed receiver gain (64), a recycle delay of $2 \mathrm{~s}$, dummy scans of 0 , an accumulation of 56 transients, temperature of $25^{\circ} \mathrm{C}$.

\section{Data processing and interpretation}

The ${ }^{1} \mathrm{H}$ NMR spectra were processed using Topspin (Bruker Topspin ${ }^{\mathrm{TM}}$, Inc) software, but it is also possible to use MestReNova ${ }^{38}$ (Mestrelab Research $\mathrm{Sl}$ ) for this purpose. Aligned spectra were baseline and phase corrected (when necessary), and referenced to tetramethyl silane (TMS) (0.00 ppm).

The processed spectra free induction decay (FID) data were opened with the MestReNova ${ }^{38}$ (other software can be used as well, such as Amix, Bruker-Biospin, Inc.) and regions that corresponded to solvent and interference signals such as solvent satellites were removed. Spectral data were treated with a binning processing function at $0.04 \mathrm{ppm}$. Data were saved in the format accepted by the statistical software to be used, in our study it was the .csv file type, which is required for MetaboAnalyst, ${ }^{39}$ the sample names and classification were typed. There are other software that can be used for NMR data binning, like NMRProcFlow ${ }^{40}$ (INRA UMR 1332 BFP, Bordeaux Metabolomics Facility) or CHENOMX NMR Suite ${ }^{41}$ (Chenomx Inc.), for example. We clarify that there are many ways of bucketing/binning NMR spectra for chemometric analysis. The bucketing in equal parts as we have suggested in this protocol is the most common way of bucketing in the literature and it is widely used.

Statistical analysis were performed using principal component analysis (PCA) and partial least squares 
discriminant analysis (PLS-DA), using a statistical software MetaboAnalyst 3.0 online platform. ${ }^{39}$ PCA and PLS-DA were performed using following the parameters: data type used was spectral bins, the format of data was sample in columns (unpaired), data preprocessing enrolled data filtering interquantile range (IQR), no sample normalization, no data transformation, and Pareto scaling (mean-centered and divided by the square root of standard deviation of each variable). Five principal components were used for discrimination of the analyzed lipid samples. Specifically, for PLS-DA, we applied leave one out cross-validation (LOOCV) as the crossvalidation method. The accuracy and variable importance in projection (VIP) were also assessed to measure the performance and important features for the analysis, respectively. Some data not attending the confidence interval (95\%) were excluded. The fish liver lipids from two fish species collected from the flood and drought seasons of the Amazon were analyzed.

\section{Quantitative NMR analysis}

Quantitative analyzes by ${ }^{1} \mathrm{H}$ NMR spectroscopy were performed at the Institutional NMR Laboratory of the Chemistry Institute of Unicamp, where the equipment used was the Bruker® high resolution $600 \mathrm{MHz}$ with a BBI probe. $100 \mu \mathrm{L}$ of the standard solution of 1,2,4,5-tetrachloro-3-nitrobenzene (5 $\mathrm{mg} \mathrm{mL}^{-1}$ ) (SigmaAldrich, USA, $99.86 \%$ purity) were added into a solution of $10 \mathrm{mg}$ of the total lipid sample previously dissolved in $500 \mu \mathrm{L}$ of deuterated chloroform $\left(\mathrm{CDCl}_{3}\right)$ with TMS. Used conditions were: $90^{\circ}$ pulse program at $25{ }^{\circ} \mathrm{C}$, an acquisition time of $8.19 \mathrm{~s}$, a spectral width of $9.9955 \mathrm{~Hz}$, $64 \mathrm{~K}$ data points a recycle delay of $40 \mathrm{~s}\left(5\right.$ times $\left.\mathrm{T}_{1}\right)$ and a number of scans of 56 . The spectra were processed using TopSpin software and integrated by setting ${ }^{1} \mathrm{H}$ integral for the internal standard (1,2,4,5-tetrachloro-3-nitrobenzene). The obtained spectra were integrated manually for the peaks of interest using TopSpin software. As lipid extracts are a mix of many compounds, which caused overlapping of NMR peaks, the quantitation was semi-quantitative and similar to already published data. ${ }^{42-45}$ The levels of linolenic and linoleic acids were calculated according to the method reported by Jiang et al. ${ }^{43}$ and expressed in molar percentages of fatty acids according to the following equations:

$$
\begin{aligned}
& \operatorname{Ln}(\%)=100 \times \frac{A_{L n}}{3 \times A_{G}} \\
& L(\%)=100 \times \frac{2 \times A_{L}}{3 \times A_{G}}
\end{aligned}
$$

where $A_{L n}$ and $A_{L}$ are the areas of the bis-allylic proton signals for linolenic and linoleic acids, respectively. $A_{G}$ is the area of the proton peaks of glyceryl groups. ${ }^{42,43}$ The chemical shifts related to each compound are described later in "Lipid analysis using ${ }^{~} \mathrm{H}$ NMR" sub-section.

\section{Results and Discussion}

\section{Material selection and collection}

The selected fishes C. monoculus and T. elongatus are piscivorous and omnivorous, respectively. Their eating habits are influenced by the dynamics of the Amazon River. The food source is higher for piscivorous fishes in drought than in flood period, where there is less water in which their preys can hide; while the opposite occurs for omnivorous fishes, which have the highest abundance of food during the flood period, when the environment is composed from flood forest and fruits that fall into the river. ${ }^{34,44-46}$

Collection of fish samples occurred at indicated six points at Catalao Lake (Figure S1, SI section) in the drought (November 24-28, 2014) and in the flood (June 02-06, 2014). The six points are representative for the Lake, which is a floodplain lake formed by the junction of the turbid waters of the Solimões River and the acids waters from Negro River. ${ }^{47}$ For this reason, it reasonable resembles all the influences of the different waters typical for the Amazon River.

The captured fishes were identified accordingly to specialized literature on Amazonian fish. ${ }^{28,34}$ A total of 22 liver samples were obtained during the flood and drought seasons (Table 1), ten samples were from the flood period, and twelve from drought.

An important factor in the collection of fish is the average length of the individuals, which indicates their sexual maturity, C. monoculus of $19 \mathrm{~cm}^{34}$ and T. elongatus of $17 \mathrm{~cm} \cdot{ }^{28}$ The fish size is important for the management and preservation of species against the impacts caused by anthropic actions such as fishing and the elimination of spawning areas and breeding grounds. ${ }^{33,48}$ On average, the length of the samples collected was higher than their respective sexual maturities, as shown in Table 1.

\section{Lipid extraction}

The Blight and Dyer ${ }^{31}$ method is a fast and efficient method and a great reference for the extraction and purification of total lipids from biological samples. . $^{33,49-51}$ A mixture of chloroform, methanol, and water must be able to extract neutral and polar lipids. This mixture is sufficiently nonpolar to break the associations with the cell 
membrane and/or lipoproteins. Furthermore, the mixture also must be sufficiently polar to release electrostatic forces and hydrogen interactions. ${ }^{31,33,50,51}$

Fish lipids are strongly related to the availability of food and energy storage. In a period in which there is a high availability of food, fish tend to store more lipids than in decreased food availability where the fish energy storage decreases because of lipid use for the maintenance of vital functions. According to the observed lipid contents, depicted in Figure 1, it is possible to see higher lipid amounts (in percentage) for both fishes during the drought.

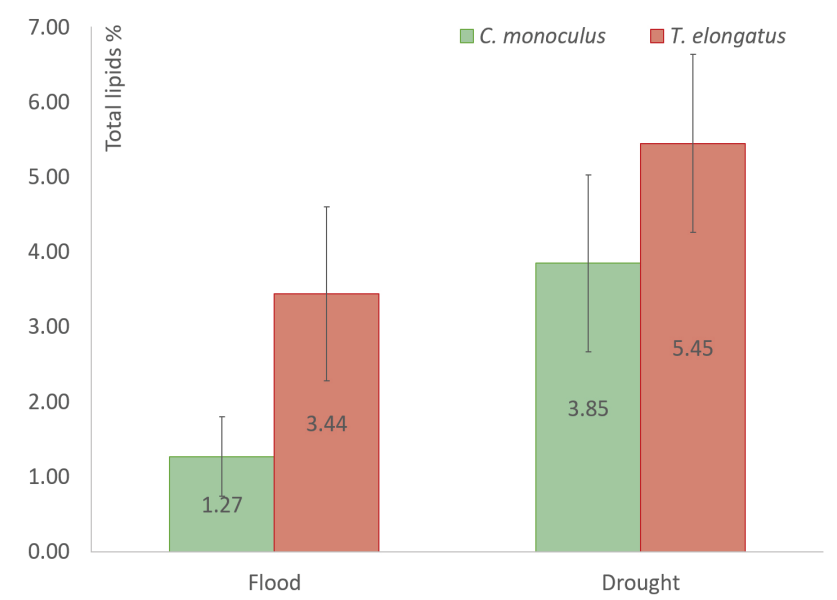

Figure 1. Lipids found in two fishes ( $\% \mathrm{~m} / \mathrm{m}$ tissue) from Amazon River.

For the C.monoculus, this variation is explained by the quantity of fish and other animals that are confined in a lower volume of water in the drought period, which facilitate the feeding of a piscivore species..$^{28,34}$ For T. elongatus, it was expected to observe higher lipid content for the flood season because of a greater availability of fruits and seeds and a larger flooded area. ${ }^{34}$ However, the opposite was detected and measured. Thus, to evaluate other, such as phenotype factor, which can influence the lipid profile of fishes, further analysis must be considered, starting from fractionation of lipids in classes of different polarities as discussed in "Fractionation of lipids" sub-section.

\section{Fractionation of lipids}

A typical class lipids extraction is the Johnston method, ${ }^{36}$ in which three different solvents are used: chloroform, acetone, and methanol. The first fraction collected is referred to the neutral lipids, more specifically, the monoacylglycerols, triacylglycerols, sterols, and free fatty acids. Then, glycolipids and medium chain fatty acids were collected during the acetone elution, as it is the second fraction. Finally, using methanol, the third fraction refers to polar lipids, such as phospholipids, characterized by having a hydrophilic portion, glycerol bound to a phosphate group, and a hydrophobic moiety, two long chains of fatty acids linked to glycerol.

The results illustrated in Figure 2 are indicative that separation process of lipid classes have ranged from 97.88 to $99.31 \%$, evidencing the high potential, performance, and efficiency of the method for this type of extraction. Regarding the analysis of the fractions of the Amazonian fishes, the class of neutral lipids is the major class among the total lipids. It can be explained by the fact that triacylglycerols, which mainly comprised neutral lipids, are involved in the processes of energy storage in the form of adipose tissue, thus, must be strictly related to the animal's food availability and the period of the year.

Due to the food habit of each species, the energy storage is higher in a given period of the year. Therefore, neutral lipids of Amazonian fishes were higher for the piscivorous fish (C. monoculus) in the drought than in the flood period. While, omnivorous fish (T. elongatus) have presented higher lipid content at the flood than in the drought period. These were expected results.

In relation to phospholipids and glycolipids classes, lipids with structural function that are components of the plasma membrane, which mostly act as a barrier to the passage of polar molecules and ions, ${ }^{51}$ was observed a minimal variation in the glycolipids content, and significant variation in phospholipids levels. In addition, we have observed that glycolipids were the class which has presented the lowest contribution in the total lipid values. Therefore, neutral lipids and phospholipids must compensate each other depending on the availability of food in the two species in each seasonal period.

Furthermore, the TLC displayed retention factors (Rfs) characteristic for lipids of high (0.00, phospholipids; 0.03 ), medium $(0.25,0.30$ glycolipids and medium chain fatty acids; $0.41,0.24$ free fatty acids and steroids), and low polarities (0.83) (Figure S2, SI section). ${ }^{33}$

A summary of the bioanalytical protocol is shown in Figure 3.

Lipid analysis using ${ }^{1} \mathrm{H}$ NMR

Along the analytical tools available for lipid profile investigation in biological samples, nuclear magnetic resonance (NMR) spectroscopy allows identifying characteristic signals from the different lipid classes..$^{52,53}$ This feature is particularly relevant in analyzing the molecular profile of foods, by allowing the identification of differences aggregated to food nutritional quality. ${ }^{42,54}$ 


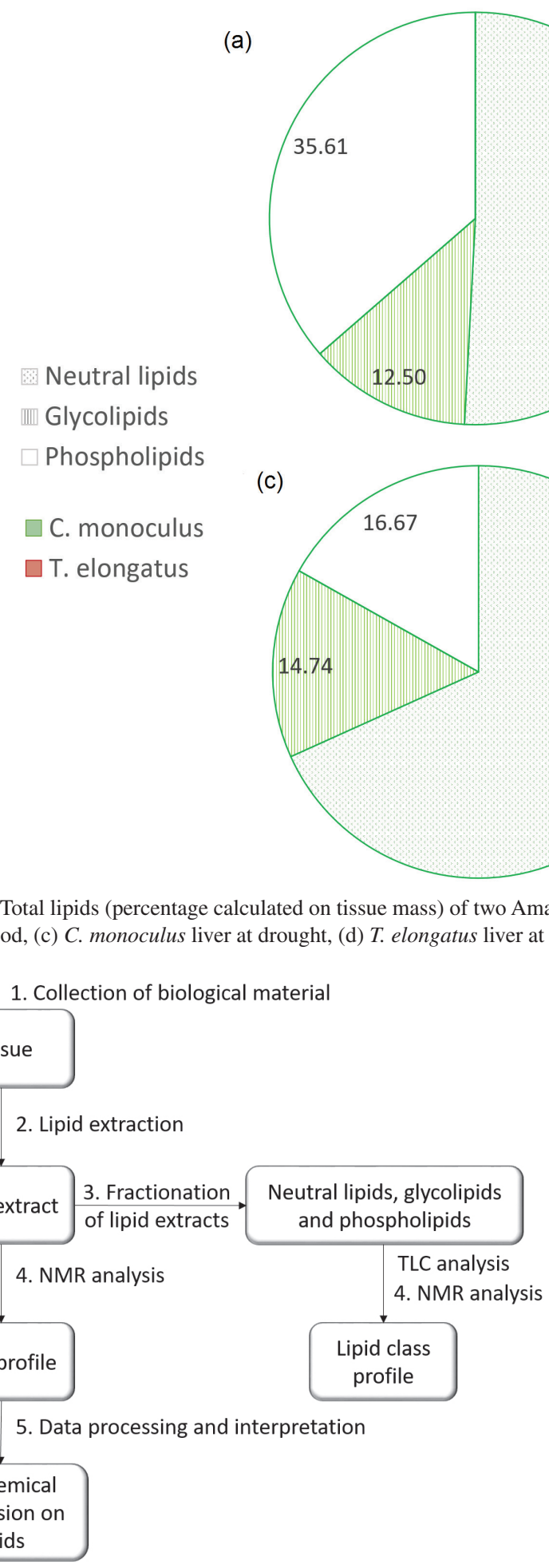

Figure 3. Analytical procedure used for fish lipids isolation and characterization.

Therefore, for the analysis of the Amazonian fishes, peaks (1-10) that are characteristic for neutral lipids, glycolipids and phospholipids were observed in the ${ }^{1} \mathrm{H}$ NMR spectra of total lipids and confirmed by posterior NMR analyses of the three fractions of lipids obtained after open column liquid chromatography fractionation. However, each lipid class has presented certain particularities, which were summarized in Table 2.

The similarity between spectra of total lipids and neutral lipids have corroborated to the information that total lipids are mostly composed from neutral lipids (peaks 11-13, Table 2). ${ }^{55-58}$ The glycolipids class have shown the corresponding peaks 1-8 in addition to the characteristic peaks of the classes, such as the peaks $14-19 .{ }^{59,61}$ As for the phospholipids, the common peaks were 1-5, 8 and 10 plus the specific peaks 20-23 (Figure S3, SI section). ${ }^{56}$ The spectral information obtained from the fractions of lipids was important for confirmation of interpretation of total lipids spectra.

Besides the peaks for each class, the comparison of the total lipids of the two species of Amazonian fishes has shown the same principal differences between them, which correspond to methylene protons of aliphatic chains (peaks 3 and $3_{1}: 1.20-1.50 \mathrm{ppm}$ ), methylene protons in the carbonyl $\alpha$-position (peaks 6: 2.20-2.50 ppm), divinyl methylene protons (peaks 7: 2.80-2.90 ppm), Sn-1 and Sn-3 protons of glycerol (peaks 8 and $8_{1}$ : 4.10-4.30 ppm), Sn-2 protons of glycerol (peaks 9 and $9_{1}: 5.25-5.50 \mathrm{ppm}$ ) and protons of double bonds with conformation $Z$ (cis, peaks 10: 5.27-5.38 ppm) as shown in Figure 4. 
Table 2. Assignment of the main resonances in ${ }^{1} \mathrm{H}$ NMR spectra of lipids isolated from the Amazonian fishes

\begin{tabular}{|c|c|c|c|}
\hline Number & $\begin{array}{c}{ }^{1} \mathrm{H} \text { NMR chemical } \\
\text { shift / ppm }\end{array}$ & Assignment & Reference \\
\hline \multicolumn{4}{|c|}{ Total lipids } \\
\hline 1 & $0.75-1.00$ & terminal methyl protons $-\mathrm{CH}_{3}$ & $2,44,55-58$ \\
\hline 2 & $0.93-1.02$ & $-\mathrm{CH}_{3}$ protons of linolenoyl chain $(\omega-3)$ & 35,58 \\
\hline 3 & $1.20-1.50$ & methylene protons of aliphatic chains $-\left(\mathrm{CH}_{2}\right)_{\mathrm{n}}$ & $2,44,55-57,59$ \\
\hline 4 & $1.50-1.75$ & $\beta$-methylene protons of the carbonyl $-\mathrm{OCO}-\mathrm{CH}_{2}-\mathrm{CH}_{2}-$ & 2,55 \\
\hline 5 & $1.95-2.10$ & methylene protons in the $\alpha$-position of double bonds $-\mathrm{CH}_{2}-\mathrm{CH}=\mathrm{CH}-$ & $55-58$ \\
\hline 6 & $2.20-2.50$ & methylene protons in the carbonyl $\alpha$-position $-\mathrm{OCO}-\mathrm{CH}_{2}-$ & $2,55,58$ \\
\hline \multirow[t]{3}{*}{7} & $2.80-2.90$ & divinyl methylene protons $=\mathrm{HC}-\mathrm{CH}_{2}-\mathrm{CH}=$ & $2,44,56$ \\
\hline & $2.79^{\mathrm{a}}$ & divinyl methylene protons $=\mathrm{HC}-\mathrm{CH}_{2}-\mathrm{CH}=$ of linoleoyl chain $(\omega-6)$ & 43 \\
\hline & $2.82^{\mathrm{b}}$ & divinyl methylene protons $=\mathrm{HC}-\mathrm{CH}_{2}-\mathrm{CH}=$ of linolenoyl chain $(\omega-3)$ & 43 \\
\hline 8 & $4.10-4.30^{c}$ & Sn- 1 and $\mathrm{Sn}-3$ protons of glycerol $=\mathrm{CH}_{2}-\mathrm{OCOR}$ & $2,55-58$ \\
\hline 9 & $5.25-5.50$ & Sn-2 protons of glycerol $>\mathrm{CH}-\mathrm{O}-\mathrm{COR}$ & $2,57,58$ \\
\hline 10 & $5.27-5.38$ & protons of double bonds with conformation $Z$ cis $-\mathbf{C H}=\mathbf{H C}-$ & $55-57$ \\
\hline \multicolumn{4}{|c|}{ Neutral lipids } \\
\hline 11 & $2.70-2.84$ & $\mathrm{CH}_{2}$-bis-allyllic protons of polyunsaturated fatty acid (PUFA) chains & $22,58,60$ \\
\hline 12 & $3.44-3.59$ & $\mathrm{CH}$ of cholesterol relative to the $\mathrm{C}-3$ proton & 35 \\
\hline 13 & $5.30-5.40$ & $\mathrm{CH}$ of cholesterol relative to the $\mathrm{C}-6$ proton of vinyl & 35 \\
\hline \multicolumn{4}{|c|}{ Glycolipids } \\
\hline 14 & $3.40-3.60$ & heteroatom proton $-\mathrm{OH}$ & 60,61 \\
\hline 15 & $3.65-3.75$ & hexoses protons on $\alpha$-carbon to the heteroatom & 60,61 \\
\hline 16 & $4.00-4.30$ & protons on $\alpha$-carbon to the heteroatom & 61 \\
\hline 17 & $4.10-4.40$ & protons on $\alpha$-carbon to the heteroatom $(\mathrm{OH})$ and $\beta$ to the amine $-\mathrm{O}-\mathrm{CH}_{2}-\mathrm{CH}_{2}-\mathrm{N}^{+}\left(\mathrm{CH}_{3}\right)_{3}$ & 61 \\
\hline 18 & 5.00 & anomeric carbon protons $\mathrm{C}^{*}$ & 48 \\
\hline 19 & $5.20-5.40$ & amine protons $-\mathbf{H N}\left(\mathrm{CH}_{3}\right)_{2}$ & 35 \\
\hline \multicolumn{4}{|c|}{ Phospholipids } \\
\hline 20 & $3.10-3.20$ & methylene protons $\alpha$ to the heteroatom $-\mathrm{CH}_{2}-\mathrm{OH}$ & 35 \\
\hline 21 & $3.20-3.40$ & methyl protons of charged nitrogen $\mathrm{N}\left(\mathrm{CH}_{3}\right)_{3}^{+}$ & $35,56,60$ \\
\hline 22 & $3.50-3.85$ & methylene protons $\alpha$ to a charged nitrogen $\mathrm{CH}_{2}-\mathrm{N}+\left(\mathrm{CH}_{3}\right)_{3}$ & $22,35,56,60$ \\
\hline 23 & $3.90-4.40$ & methylene protons $\alpha$ to the heteroatom connected to phosphorus $\mathrm{CH}_{2}-\mathrm{O}-\mathrm{P}$ & 35,56 \\
\hline
\end{tabular}

a Linoleic acid (L); 'blinolenic acid (Ln), ${ }^{\text {gglycerol }(G) .}$

\section{Chemometrics and interpretation}

As the data obtained in lipid analysis and prospection of many samples by NMR are large, it is necessary to process them through multiple statistical tools, using chemometrics. The multivariate statistical analysis and their consequent interpretation must be able to contribute to identifying action mechanisms on phenotype conditions in this case. ${ }^{8,9}$

The partial least squares discriminant analysis (PLS-DA) has been extensively used in the analysis of multivariate datasets, such as that derived from NMR-based metabolomics. It is a supervised multivariate regression method that optimizes the separation between groups of observations by rotating the principal component analysis (PCA) in order to obtain the maximum separation between the classes. These analyses were based on the data matrix of intensities of the chemical shifts from the ${ }^{1} \mathrm{H}$ NMR spectra of total lipids of the Amazonian fishes, seeking to evidence variables responsible for the distinguishing of the phenotype factors, i.e., availability of types of foods according to eating habits during different seasons.

The results of the PLS-DA score plot have demonstrated the great influence of season on the species differentiation, once $88.7 \%$ of the chemical shift information can be represented by only three components (Figure 5). The latent 


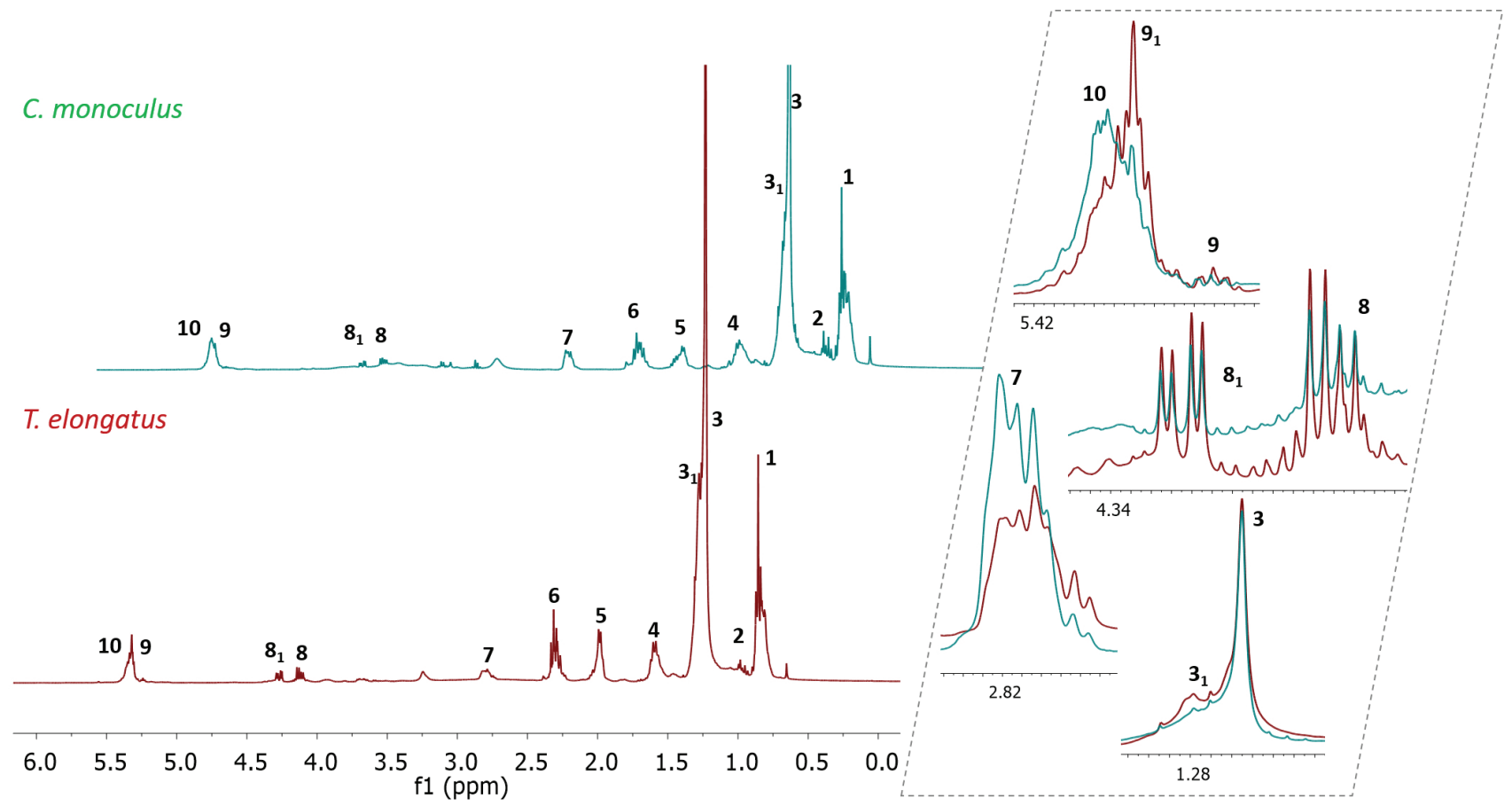

Figure 4. ${ }^{1} \mathrm{H}$ NMR spectra obtained from the total lipids extracted from the liver of $C$. monoculus and T. elongatus. Assignments are shown according to ones given in Table 2. The most important peaks are amplified at the right. Chemical shifts: 5.38-5.30 (m, 2H) (10); $5.28(\mathrm{~s}, 1 \mathrm{H})\left(9_{1}\right) ; 5.24(\mathrm{t}, J 5.1 \mathrm{~Hz}$, $1 \mathrm{H})(9) ; 4.27(\mathrm{dd}, J 11.9,4.3 \mathrm{~Hz}, 1 \mathrm{H})\left(8_{1}\right) ; 4.12(\mathrm{dd}, J 12.0,6.0 \mathrm{~Hz}, 1 \mathrm{H})(8) ; 2.81(\mathrm{dt}, J 21.2,5.5 \mathrm{~Hz}, 2 \mathrm{H})(7) ; 2.29(\mathrm{td}, J 7.6,3.5 \mathrm{~Hz}, 2 \mathrm{H})(6) ; 2.02(\mathrm{dq}$, $J 32.1,7.2,6.6 \mathrm{~Hz}, 2 \mathrm{H})(5) ; 1.62-1.55(\mathrm{~m}, 2 \mathrm{H})(4) ; 1.28(\mathrm{~d}, J 9.5 \mathrm{~Hz}, 10 \mathrm{H})\left(3_{1}\right) ; 1.23(\mathrm{~s}, 12 \mathrm{H})(3) ; 1.02-0.93(\mathrm{~m}, 1 \mathrm{H})(2) ; 0.92-0.79(\mathrm{~m}, 4 \mathrm{H})(1)$.
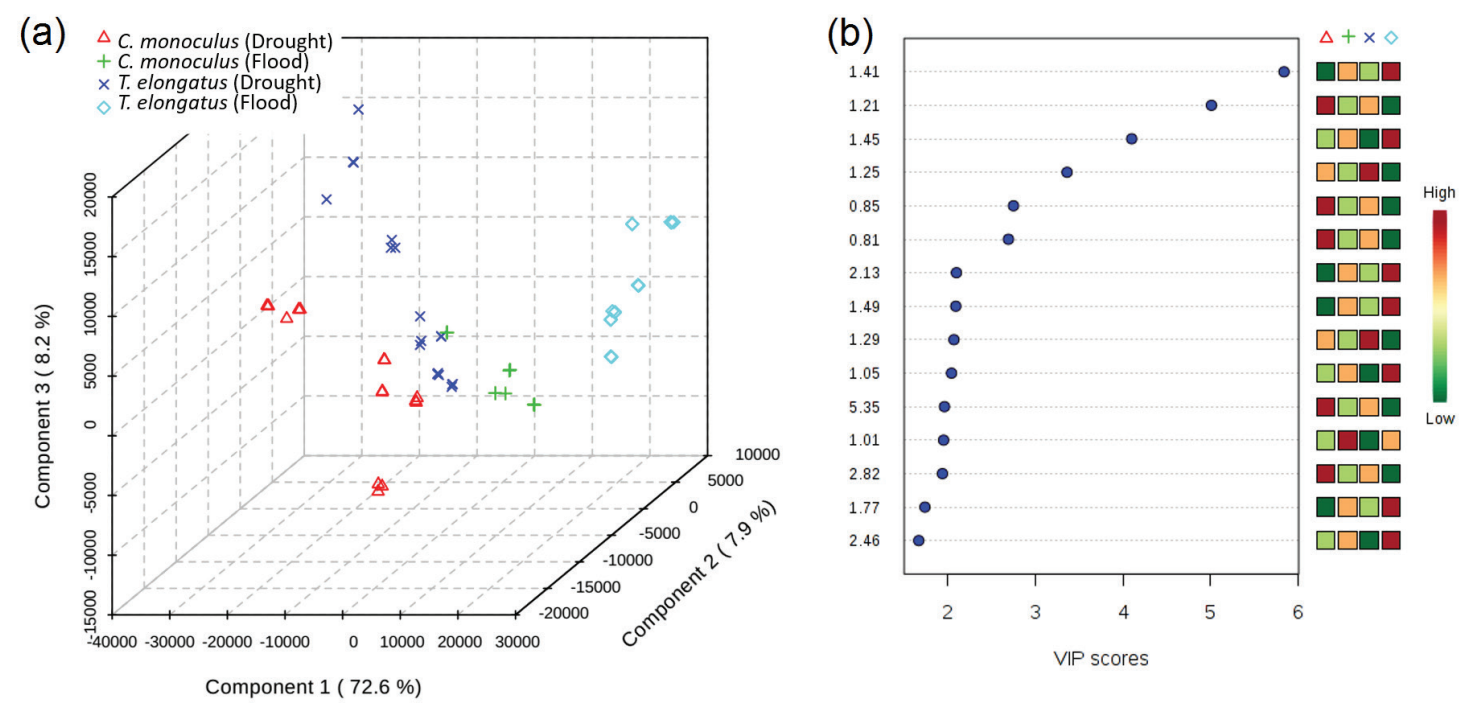

Figure 5. PLS-DA score chart (a) and variable importance in projection (VIP) (b) of the Amazonian fishes C. monoculus and T. elongatus from flood and drought periods.

variable (LV) 1 has explained $72.6 \%$ of the data variance, while LV 2 explained $7.9 \%$ and LV 3, 8.2\% (Figure 5a).

Thus, the result of the lipid profile of liver samples of Amazonian fish from both periods have evidenced the formation of two distinct groups in LV 1, separating the samples according to the period of the year, where the T. elongatus and C. monoculus scores of the flood presented positive values; while for the drought period, both presented negative values in LV 1. In addition, for the flood period, the species can be separated in LV 2, whereas the T. elongatus scores presented positive values while $C$. monoculus presented negative ones. Therefore, using PLS-DA, it was possible to separate the lipids according to the seasonal influences of the Amazon region, which shows that, besides the intrinsic characteristics of each species, i.e., their eating habits, the amount and composition of lipids of both species are influenced by the variations of the environment, in this case, the Amazonian hydrological cycle. The highest lipid 
Table 3. PLS-DA cross validation details

\begin{tabular}{lllllllll}
\hline Measure & $1 \mathrm{LV}$ & $2 \mathrm{LV}$ & $3 \mathrm{LV}$ & $4 \mathrm{LV}$ & $5 \mathrm{LV}$ & $6 \mathrm{LV}$ & $7 \mathrm{LV}$ & $8 \mathrm{LV}$ \\
\hline Accuracy & 0.440 & 0.720 & 0.777 & 1.000 & 1.000 & 1.000 & 1.000 & 1.000 \\
$\mathrm{R}^{2}$ & 0.365 & 0.727 & 0.817 & 0.870 & 0.919 & 0.949 & 0.964 & 0.976 \\
$\mathrm{Q}^{2}$ & 0.301 & 0.673 & 0.772 & 0.804 & 0.846 & 0.884 & 0.913 & 0.956 \\
\hline
\end{tabular}

$\mathrm{LV}$ : latent variable; $\mathrm{R}^{2}$ : coefficient of determination; $\mathrm{Q}^{2}$ : quality assessment values.

composition occurred for T. elongatus during the flood period, when the species had greater availability of food, thus acquired greater energy storage.

Since PLS-DA have an innate tendency to overfit data, the statistical model needs to be validated in order to understand whether the separation is statistically significant or completely random. Table 3 shows the values of accuracy, the coefficient of determination $\left(\mathrm{R}^{2}\right)$ and the quality assessment values $\left(\mathrm{Q}^{2}\right)$.

According to the results, the higher the number of components used for building the model, the better it is, as statistics showed $97.646 \%\left(\mathrm{R}^{2}=0.976\right)$ of the variables responsible for the grouping, when 8 components were used, besides of being a point with maximum accuracy and high values of $\mathrm{Q}^{2}$. However, since the model accuracy is already maximum at component 4 , just 4 components are sufficiently reliable to separate the data into the groups. Also, components 1-4 at the variables importance in projection (VIP) chart have showed similar results.

The variables importance in projection (VIP) (Figure 5b) and the loading charts (Figure S4, SI section) show the specific values of NMR shifts (ppm) responsible for clustering in order of decreasing relevance. The most relevant NMR shifts were correlated to the signals numbered as $3(1.41,1.25,1.21,1.45,1.29$ and $1.37 \mathrm{ppm}), 7$ (2.94 and $2.82 \mathrm{ppm}), 1$ (0.81, $0.85 \mathrm{ppm})$ and $10(5.43 \mathrm{ppm})$ in order of importance. These peaks correspond to methylene protons of aliphatic chains, divinyl methylene protons, terminal methyl protons and protons of double bonds with conformation $Z$ ( $c i s$ ), respectively. Other important chemical shifts were 2 (1.01 ppm), 5 (2.13 ppm), $6(2,38 \mathrm{ppm})$, and 21 (3.38 ppm), which are related to methyl protons of linolenoyl chain and methylene protons in the $\alpha$-position of double bonds, methylene protons in the carbonyl $\alpha$-position and methyl protons of charged nitrogen (Figure 4 and Table 2), respectively.

\section{Quantification of linolenic and linoleic acids}

The linolenic (18:3n-3) and linoleic (18:2n-6) acids are known for their benefits to the human organism associated with a balanced diet, working as sources for $\omega-3$ polyunsaturated fatty acids (PUFA) as the docosahexaenoic acid (DHA, 22:6n-3) and the eicosapentaenoic acid (EPA, $20: 5 n-3$ ), and $\omega-6$ PUFA as the arachidonic acid (AA, 20:4n-6). ${ }^{8,9}$ These two families are associated with important functions in the metabolic and structural processes of the cell membrane, besides being related to the prevention of several diseases as cardiovascular, inflammatory diseases, neurological, visual and behavioral disorders, as well as, influencing human growth and development. ${ }^{8,9,15,17,19}$

In addition, it is important to mention that the population of the region, especially the riverine population, is culturally dependent on fish for their daily nutritional sustenance. These populations benefit from fish as an excellent source of essential nutrients, proteins, vitamins, minerals and fatty acids. PUFA DHA and EPA are abundant in fish lipids as part of the fraction of neutral lipids, ${ }^{15}$ the largest fraction found proportionally in both species.

Considering the quantities obtained for each species in each season, it can be affirmed that for C. monoculus there is an evident increase of the $\omega-6: \omega-3$ ratio and consequent accumulation of $\omega-6$ fatty acids during the period of flood, a time of greater food availability, while for T. elongatus there was not a significant change in the $\omega-6: \omega-3$ ratio as shown in Figure 6. This can be explained by the nutritional values of the food consumed by each species, T. elongatus feeds mainly on seeds and fruits, which do not have high nutritional values and are not great sources of $\omega-6$ lipids.

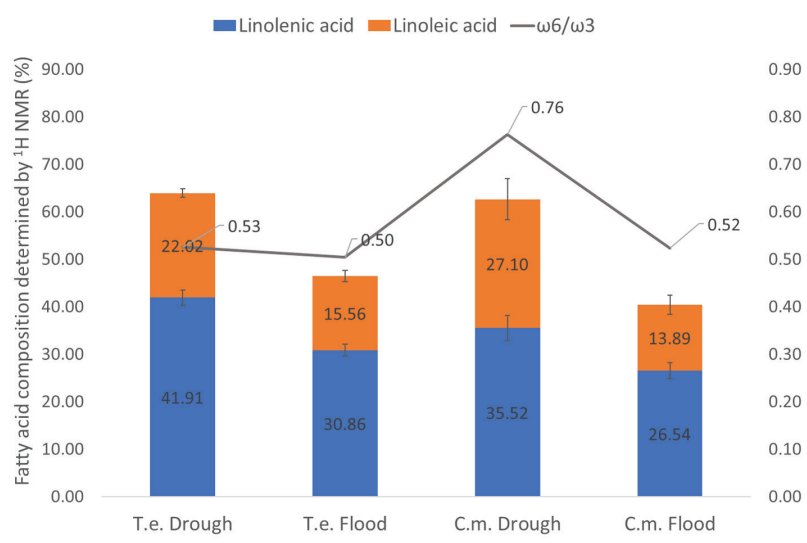

Figure 6. Changes in the fatty acid compositions (percentage of linolenic and linoleic acids) of T. elongatus (T. e.) and C. monoculus (C. m.) at each Amazon River periods, drought and flood, determined by ${ }^{1} \mathrm{H}$ NMR. 
Therefore, regardless of the period, the rate $\omega-6: \omega-3$ does not change considerably. The opposite is obtained for C. monoculus, which as a piscivorous, feeds on other fish that are sources of PUFA $\omega-6$ and $\omega-3$, so there is a considerable increase in the $\omega-6: \omega-3$ ratio due to the amount of energy envisaged in its diet, generating a lipid (triacylglycerols) accumulation.

Ultimately, according to the results obtained in this study, there are differences among the types of liver lipids between C. monoculus and T. elongatus due to the seasonal and dietary effects. Neutral lipids and the phospholipids are the lipid classes responsible for the major differentiation of the same species during flood and drought period. Dietary habits of species change the liver lipids composition greatly when compared flood and drought, because of the availability of food. Furthermore, fish-eating habits influence the synthesis of fatty acids of various size and unsaturation degree.

\section{Conclusions}

An easy to follow protocol for fish lipid extraction and analysis by NMR spectroscopy was developed and tested for two Amazonian fishes. It was demonstrated that the ${ }^{1} \mathrm{H}$ NMR spectroscopy followed with chemometrics, named lipidomics by NMR, showed to be an excellent methodology for the characterization of the fish lipid molecules. There are numerous factors that could influence the lipid composition among the fish species, but according to the analyzed data, the most evident factors are the degree of insaturations and the size of the fatty acid chains. Also, amount of lipids can vary among the species, such as in the case of T. elongatus, which showed a higher total lipid content than the $C$. monoculus. Nevertheless, polar glycolipids seem to maintain their quantity and contents, independently to external phenotype factor influences. On the other hand, neutral lipids and phospholipids showed an opposite tendency in quantities because of the external phenotype factor influences and showed that compensate each other depending on the availability of food that two fish species had in each seasonal period. Therefore, glycerol availability for neutral lipids synthesis is probably regulated by the quantity of food available for feeding, when the food is scarce, glycerol is more frequently used for polar phospholipids synthesis.

\section{Supplementary Information}

Supplementary information is available free of charge at http://jbcs.sbq.org.br as a PDF file.

\section{Acknowledgments}

FAPESP (Fundação de Amparo à Pesquisa do Estado de São Paulo) for the scholarships given to BSBC $(\mathrm{PhD}$, process No. 2013/14707-9) and NCM (scientific initiation, process No. 2014/11258-1) is kindly acknowledged.

\section{References}

1. Barriuso, B.; Astiasarán, I.; Ansorena, D.; Eur. Food Res. Technol. 2013, 236, 1.

2. Cai, H.; Lin, L.; Ding, S.; Cui, X.; Chen, Z.; Eur. J. Lipid Sci. Technol. 2016, 118, 1150.

3. Kostara, C. E.; Papathanasiou, A.; Psychogios, N.; Cung, M. T.; Elisaf, M. S.; Goudevenos, J.; Bairaktari, E. T.; J. Proteome Res. 2014, 13, 2585.

4. Knothe, G.; Kenar, J. A.; Eur. J. Lipid Sci. Technol. 2004, 106, 88.

5. Igarashi, T.; Aursan, M.; Hirata, Y.; Gribbestad, I. S.; Wada, S.; Nonaka, M.; J. Am. Oil Chem. Soc. 2000, 77, 737.

6. Ouldamer, L.; Nadal-Desbarats, L.; Chevalier, S.; Body, G.; Goupille, C.; Bougnoux, P.; J. Proteome Res. 2016, 15, 868.

7. Rolim, A. E. H.; Henrique-Araújo, R.; Ferraz, E. G.; Dultra, F. K. A. A.; Fernandez, L. G.; Gene 2015, 554, 131.

8. Martin, C. A.; Almeida, V. V.; Ruiz, M. R.; Visentainer, J. E. L.; Matshushita, M.; Souza, N. E.; Visentainer, J. V.; Rev. Nutr. 2006, 19, 761 .

9. Tinoco, S. M. B.; Sichieri, R.; Moura, A. S.; Santos, F. S.; Carmo, M. G. T.; Cad. Saúde Pública 2007, 23, 525.

10. Luzia, L. A.; Sampaio, G. R.; Castellucci, C. M. N.; Torres, E. A. F. S.; Food Chem. 2003, 83, 93.

11. Simopoulos, A. P.; Exp. Biol. Med. 2008, 233, 674.

12. Vance, D. E.; Vance, J. E.; Biochemistry of Lipids, Lipoproteins and Membrane, $4^{\text {th }}$ ed.; Elsevier Science: Amsterdam, The Netherlands, 2002.

13. Voet, D.; Voet, J. G.; Pratt, C. W.; Fundamentos de Bioquímica, $1^{\text {st }}$ ed.; Artmed: Porto Alegre, Brazil, 2006.

14. Wagner, L.; Trattner, S.; Pickova, J.; Gómez-Requeni, P.; Moazzami, A. A.; Food Chem. 2014, 147, 98.

15. Almeida, N. M.; Franco, M. R. B.; J. Sci. Food Agric. 2007, 87, 2596.

16. Bentes, Á. S.; de Souza, H. A. L.; Simões, M. G.; Mendonça, X. M. F. D.; Rev. Bras. Tecnol. Agroindustrial 2009, 3, 97.

17. Cheng, K.; Wagner, L.; Moazzami, A. A.; Gómez-Requeni, P.; Vestergren, A. S.; Brannas, E.; Pickova, J.; Trattner, S.; Eur. J. Lipid Sci. Technol. 2016, 118, 862.

18. Carmo, M. C. N. S.; Correia, M. I. T. D.; Rev. Bras. Cancerol. 2009, 55, 279.

19. de Caterina, R.; Basta, G.; J. Suppl. 2001, 3, D42.

20. Inhamuns, A. J.; Franco, M. R. B.; Batista, W. S.; Food Chem. 2009, 117, 272. 
21. Keriko, J. M.; Chege, C. W.; Magu, M. M.; Mwachiro, E. C.; Murigi, A. N.; Githua, M. N.; Kareru, P. G.; Afr. J. Pharm. Pharmacol. 2010, 4, 745.

22. Lunn, J.; Theobald, H. E.; Nutr. Bull. 2006, 31, 178.

23. Gurr, M.; Harwood, J.; Frayn, K.; Lipid Biochemistry: An Introduction, $5^{\text {th }}$ ed.; Blackell Publishing: Malden, USA, 2002.

24. Ruiz-Lopez, N.; Stubhaug, I.; Ipharraguerre, I.; Rimbach, G.; Menoyo, D.; Mar. Drugs 2015, 13, 4255.

25. Ruffino, M. L.; da Silva, C. O.; Viana, J. P.; Barthem, R. B.; Fabré, N. N.; Batista, V. S.; Victoria, J. I. In A Pesca e os Recursos Pesqueiros na Amazônia Brasileira; Ruffino, M. L., ed.; ProVárzea: Manaus, Brazil, 2004.

26. Sacchi, R.; Medina, I.; Aubourg, S. P.; Addeo, F.; Paolillo, L.; J. Am. Oil Chem. Soc. 1993, 70, 225.

27. Sales, R. O.; Maia, E. L.; Rev. Bras. Hig. Sanid. Anim. 2013, 7,31 .

28. Santos, G.; Ferreira, E.; Zuanon, J.; Peixes Comerciais de Manaus; $2^{\text {nd }}$ ed.; ProVárzea: Manaus, Brazil, 2006.

29. Fahy, E.; Subramanian, S.; Brown, H. A.; Glass, C. K.; Merrill, A. H.; Murphy, R. C.; Raetz, C. R. H.; Russel, D. W.; Seyama, Y.; Shaw, W.; Shimizu, T.; Spener, F.; Meer, G. V.; VanNieuwenhze, M. S.; White, S. H.; Witztum, J. L.; Dennis, E. A.; J. Lipid Res. 2005, 46, 839.

30. Brugger, B.; Аnnu. Rev. Biochem. 2014, 83, 79.

31. Bligh, E. G.; Dyer, W. J.; Can. J. Biochem. Physiol. 1959, 37, 911.

32. Gunstone, F. D.; The Chemistry of Oils and Fats: Sources, Composition, Properties and Uses, $1^{\text {st }}$ ed.; Blackwell Publishing: Oxford, United Kingdom, 2004.

33. Brum, A. A. S.; Arruda, L. F.; Regitano-D'Arce, M. A. B.; Quim. Nova 2009, 32, 849.

34. Soares, M. G. M.; da Costa, E. L.; Siqueira-Souza, F. K.; dos Anjos, H. D. B.; Yamamoto, K. C.; Freitas, C. E. C.; Peixes de Lagos do Médio Rio Solimões, $2^{\text {nd }}$ ed.; Instituto Ipiatam: Manaus, Brazil, 2008.

35. Truzzi, C.; Illuminati, S.; Annibaldi, A.; Antonucci, M.; Scarponi, G.; Chemosphere 2017, 173, 116.

36. Johnston, J. J.; Ghanbari, H. A.; Wheeler, W. B.; Kirk, J. R.; J. Food Sci. 1983, 48, 33.

37. Fuchs, B.; Süß, R.; Teuber, K.; Eibisch, M.; Schiller, J.; J. Chromatogr. A 2011, 1218, 2754.

38. Mestrelab Research; MestreNova, version 6.2.0; Mestrelab, Spain, 2010.

39. http://www.metaboanalyst.ca/faces/home.xhtml, accessed on February 2019.

40. NMRProcFlow40, INRA UMR 1332 BFP, Bordeaux Metabolomics Facility, France.
41. Chenomx Inc.; Chenomx NMR Suite; Chenomx Inc., Edmonton, Canada.

42. Guillen, M. D.; Carton, I.; Goicoechea, E.; Uriarte, P. S.; J. Agric. Food Chem. 2008, 56, 9072.

43. Jiang, X.; Huang, R.; Wu, S.; Wang, Q.; Zhang, Z.; J. Food Meas. Charact. 2018, 12, 1420.

44. Guillen, M. D.; Ruiz, A.; Trends Food Sci. Technol. 2001, 12, 328.

45. Vidal, N. P.; Manzanos, M. J.; Goicoechea, E.; Guillén, M. D.; Food Chem. 2012, 135, 1583.

46. Junk, W. J.; Soares, M. G.; Aquat. Ecosyst. Health Manage. 2001, 4, 437.

47. Brito, J. G.; Alves, L. F.; Espirito, H. M. V.; Acta Amazonica 2014, 44, 121.

48. Cantanhêde, L. G.; Carvalho, I. F. S.; Santos, N. B.; Almeida, Z. S.; Acta Amazonica 2016, 46, 219.

49. Iverson, S. J.; Lang, S. L. C.; Cooper, M. H.; Lipids 2001, 36, 1283.

50. Constantino, A. F.; Lacerda Jr., V.; dos Santos, R. B.; Greco, S. J.; Silva, R. C.; Neto, A. C.; Barbosa, L. L.; de Castro, E. V. R.; Freitas, J. C. C.; Quim. Nova 2014, 37, 10.

51. Silva, L. R.; Ferreira, M. M. C.; Quim. Nova 2003, 26, 312.

52. Lutz, N. W.; Sweedler, J. V.; Wevers, R. A.; Methodologies for Metabolomics: Experimental Strategies and Techniques; Cambridge University Press: New York, USA, 2013.

53. Wenk, M. R.; Nat. Rev. Drug Discov. 2005, 4, 594.

54. Capozzi, F.; Bordoni, A; Genes Nutr. 2013, 8, 1.

55. Colzato, M.; Forato, L. A.; Colnago, L. A.; Assis, O. B. G.; Análise Comparativa dos Espectros de ${ }^{1} H$ RMN de Óleos Comestíveis Oxidados; Embrapa: São Carlos, 2008. Available at https://www.infoteca.cnptia.embrapa.br/bitstream/doc/31726/1/ CT922008.pdf accessed on September 2019.

56. Gaede, H. C.; Stark, R. E.; Lab. 2001, 78, 1248.

57. Vlahov, G.; Prog. Nucl. Magn. Reson. Spectrosc. 1999, 35, 341.

58. Siciliano, C.; Belsito, E.; de Marco, R.; di Gioia, M. L.; Leggio, A.; Liguori, A.; Food Chem. 2013, 136, 546.

59. Rezzi, S.; Giani, I.; Héberger, K.; Axelson, D. E.; Moretti, V. M.; Reniero, F.; Guillou, C.; J. Agric. Food Chem. 2007, 55, 9963.

60. Brindle, J. T.; Antti, H.; Holmes, E.; Tranter, G.; Nicholson, J. K.; Bethell, H. W. L.; Clarke, S.; Schofield, P. M.; McKilligin, E.; Mosedale, D. E.; Drainger, D. J.; Nat. Med. 2002, 8, 1439. 61. Lulianelli, G. C. V.; Tavares, M. I. B.; Polímeros 2011, 21, 131.

Submitted: June 19, 2019

Published online: September 26, 2019 